\title{
No tempo de Sagarana
}

Sônia Maria van Dijck Lima I UFPB

Resumo: Verificamos a recepção crítica de Sagarana, considerando o contexto pós-Estado Novo, resultando em sua entrada no cânone da Literatura brasileira.

Palavras-chave: narrativa, estética da recepção, cânone.

Conforme lição de H. R. Jauss (1978, p. 56),

a recepção de um texto pressupõe sempre o contexto de experiência anterior no qual se inscreve a percepção estética: o problema da subjetividade da interpretação e do gosto do leitor isolado ou em diferentes categorias de leitores não pode ser colocado de forma pertinente, se não se tem inicialmente reconstituído este horizonte de uma experiência estética intersubjetiva preliminar que funda toda compreensão individual de um texto e o efeito que ele produz.

Em outras palavras: a recepção estética faz-se nos contornos canônicos de um "horizonte de expectativa" (Jauss, 1978, p. 54 e segs.). Sendo que "cada época e cada grupo social têm seu repertório de formas de discurso na comunicação sócio-ideológica” (Bakhtin, 1988, p. 43).

Nos parâmetros de um cânone já habitado por José de Alencar e Franklin Távora, desde o século XIX, e José Américo de Almeida, a partir de 1928, a questão de uma literatura da terra e da gente brasileiras, antecede, 
percorre e ultrapassa a polêmica das várias correntes do Modernismo, em demanda de uma expressão nacional, cuja unidade se constrói na diversidade de linguagens e de comportamentos culturais, vindos do processo histórico de colonização e conquista do vasto território brasileiro.

Revelado ao público em abril de 1946, Sagarana encontrou um horizonte de expectativa interessado no regionalismo; leitores voltados para a busca de um reconhecimento de uma identidade nacional, não importando a tonalidade política desse ou daquele autor ou crítico, desse ou daquele grupo de artistas e intelectuais. Dentro de um clima ideológico forjado pela Revolução de 30 e construído pela força do Estado Novo, aos intelectuais eram solicitadas atitudes de apoio e de conivência, ou de oposição e contestação, em relação ao projeto político-ideológico formulado pelo governo.

Assim é que a alternativa marcante do período reside nos estudos sobre o passado, e, no limite, em uma literatura voltada para as regiões afastadas do centro de poder e de decisão. Conforme lição de Bakhtin (1988, p. 37) "a palavra (...) é neutra em relação a qualquer função ideológica específica. Pode preencher qualquer espécie de função ideológica: estética, científica, moral, religiosa."

\section{O Brasil de Sagarana}

Para a formação da cultura e da literatura nacionais, conta-se com a contribuição de uma literatura de divulgação das riquezas da terra e das características de sua gente. Essa literatura atravessa o localismo nativista dos tempos da colonização, para um mergulho no nacionalismo romântico. Com o Modernismo, "procura-se, forma-se e revela-se não uma, mas novas imagens do país, divergentes conforme as diversidades de seus aspectos, características e problemas regionais" (Castello, 1999, v. 2, p.72). Do ponto de vista político e cultural, o Brasil entra na década de 30 do século XX sem abandono da perspectiva de unidade, numa realidade de muitas desigualdades políticas e sociais, habitada, incluive, por imigrantes e seus descendentes.

No panorama político dos anos 30 e até 1946, o Estado impunha uma ideologia nacionalista, movida pelo anseio de modernização e emoldurada pelo populismo político tão bem exercitado por Getúlio Vargas, que, na convivência com os vários grupos oligárquicos, conhecia as diferenças regionais. Dessa época foram a criação da Vale do Rio Doce, do DNER, da 
Companhia Siderúrgica Nacional, da Companhia Hidrelétrica do São Francisco, como marcos da vertente modernizadora do programa getulista.

Todavia, a atualização literária das diversidades nacionais, ou da demanda da brasilidade, não se fez sem as dificuldades criadas por esse mesmo espírito nacionalista, como programa político.

No contexto intelectual e artístico, João Luiz Lafetá (2000, p. 30) salienta que havia uma atitude de "politização", donde uma preocupação com os problemas sociais, o gosto pelos ensaios históricos e sociológicos, e, em conseqüência,

o romance de denúncia, a poesia militante e de combate. (...) os escritores e intelectuais esquerdistas mostram a figura do proletariado (Jubiabá, por exemplo) e do camponês (Vidas secas) instando contra as estruturas que os mantêm em estado de sub-humanidade.

O período foi de contradições, conforme se pode notar nas observações do crítico:

por outro lado, o conservadorismo católico, o tradicionalismo de Gilberto Freyre, as teses do integralismo, são maneiras de reagir contra a própria modernização. (...) A Revolução de 30, com a grande abertura que traz, propicia - e pede - o debate em torno da história nacional, da situação de vida do povo no campo e na cidade, do drama das secas etc. O real conhecimento do país faz-se sentir como uma necessidade urgente e os artistas são bastante sensibilizados por essa exigência (Lafetá, 2000, p. 32).

Na criação literária, buscava-se o coloquial e o regional, empregandose mesmo o calão e o palavrão; numa perspectiva realista, e até mesmo um tanto documental, procurava-se traduzir o "real", e, logo, aparecem aqueles acusados de construtores de "cenas fortes". Em suas memórias, depõe Nelson Werneck Sodré (1970, p. 106): "Romances de Jorge Amado e de José Lins do Rego foram para as fogueiras purificadoras; as bibliotecas sofreram buscas e delas, banidos como heréticos, esses livros, licenciosos para a nova pudicícia, foram retirados com alarde."

Leve-se em conta que, nos anos 30, a crítica literária, com seu caráter militante e sua presença nos rodapés dos periódicos, era recente, e tributária dos modelos franceses do século XIX, mas dispensando-se do rigor 
de princípios estéticos ou filosóficos. Carecendo de bases teóricas firmes e de critérios metodológicos definidos, a crítica era feita comparativamente, dando margem à exibição do eruditismo dos titulares de colunas, que invocavam suas muitas leituras como instrumento para a compreensão de um novo livro, de acordo com o "horizonte de expectativa".

Por outro lado, vê-se que o debate capaz de conduzir ao "real conhecimento do país", de que fala Lafetá, convivia com as dificuldades e os limites impostos pelo regime de Vargas. Contudo, os intelectuais não estavam infensos ao apelo nacionalista. "Nenhum sistema entre nós jamais foi tão nacionalista, no seu conteúdo e na sua essência”, escreveu Monte Arrais, elogiando o período de Vargas (1938, p. 25). No mais perfeito proselitismo getulista, André Carrazzoni (1939, p. 170) explicou:

A política de sadio nacionalismo, sem exageros jacobinistas; de amparo ao trabalho e às classes trabalhistas, numa legislação social de ritmo evolutivo; de sindicalização de operários e patrões; de valorização da terra e do homem; de propulsão das riquezas permutáveis, com a intervenção moderada do poder público e o desenvolvimento dos meios de transporte; de combate ao latifúndio, no estímulo à democratização da terra, através da pequena propriedade; de desapoio sistemático às indústrias artificiais; essa política previdente e providente, integral e tutelar, racional e prática, a um tempo conservadora e revolucionária, são os pontos cardiais da orientação do sr. Getúlio Vargas, chefe do governo e homem de Estado.

Tendo uma primeira versão em 1937, para o Prêmio Humberto de Campos, e aparecendo como livro meses depois de findo o Estado Novo, Sagarana insere-se nas contradições de seu tempo e ocupa o centro do debate crítico em torno do regionalismo, ao longo de 1946.

\section{O sucesso de Sagarana}

O anúncio de O Globo (Rio de Janeiro), de 29 de abril, traduz o clima instaurado: "O livro do momento. SAGARANA. J. Guimarães Rosa. Já está à venda em todas as livrarias".

1. Anúncio. Arq. JGR-IEB/USP-R2. 
Esgotado em poucos dias, já se falava em segunda edição em maio do mesmo ano, conforme reportagem de Ascendino Leite (ver em seguida); esse fato foi confirmado em nota, de 30 de junho, de O Jornal (Rio de Janeiro): "convém lembrar que se esgotou em poucos dias a primeira edição de Sagarana, (...). A Editora Universal já está mesmo cogitando de lançar a segunda edição, tantos são os pedidos que não puderam ser atendidos."

A segunda edição foi anunciada na coluna "Livros", de A Noite (Rio de Janeiro), no dia 30 de julho, salientando que a publicação estava destinada "a atender aos inúmeros amigos dos bons livros que não haviam conseguido adquirir a obra no lançamento inicial." ${ }^{3}$

O livro foi sucesso de vendas, apesar do selo de uma editora pequena, que estreava no mercado, ${ }^{4}$ embora não deva ter tido uma grande tiragem na primeira edição. Por outro lado, o público leitor da década de 40 não deve ser encarado pelas nossas medidas de hoje, ainda que, na opinião de Almeida Fischer (1946), o interesse pelo livro de contos já fosse, em 1946, bem maior do que vinte anos antes.

\section{A atitude da crítica}

Embora tratado como estreante, em 1946, Guimarães Rosa já havia sido laureado com alguns prêmios, sendo o mais significativo o $1^{\circ}$ Prêmio de Poesia da Academia Brasileira de Letras, com Magma, no dia 29 de junho de 1937. Todavia, faltava o livro, para apresentar o autor a seus críticos.

Diante de Sagarana, coube a Álvaro Lins (1946) o batismo crítico de Guimarães Rosa, logo após o lançamento de abril de 1946:

De repente, chega-nos o volume, e é uma grande obra que amplia o território cultural de uma literatura, que lhe acrescenta alguma coisa de

\section{Nota. Arq. JGR-IEB/USP-R2.}

3. Nota. Arq. JGR-IEB/USP-R2.

4. O editor foi Caio Pinheiro, redator da Tribuna da Imprensa, tendo inaugurado a Editora Universal com Sagarana. Cf. O primeiro editor de "Sagarana". Tribuna da Imprensa, Rio de Janeiro, 10 abr. 1956. Hoje nas Letras. Arq. JGR-R1.

5. Magma permaneceu inédito até 1997, quando foi editado pela Nova Fronteira (Rio de Janeiro). 
novo e insubstituível, ao mesmo tempo que um nome de escritor, até ontem ignorado do público, penetra ruidosamente na vida literária para ocupar desde logo um dos seus primeiros lugares. O livro é "Sagarana" e o escritor é o sr. J. Guimarães Rosa.

Ao ensaio do consagrado crítico Álvaro Lins, que não deixou de apontar em alguns momentos do livro "uma certa fragilidade na ação novelística”, seguiram-se, ao longo de 1946, resenhas, notas assinadas e outras da responsabilidade da redação dos periódicos, reportagens, novos ensaios; colunas dedicaram-se a falar do autor e da obra; jornais apressaram-se a pedir entrevistas ao autor, e João Condé conseguiu um depoimento sobre a gênese da obra. ${ }^{6}$ Ofereceram-se ao leitor trechos do livro como "Um 'trailler' de 'Sagarana", 7 independentemente das inúmeras citações feitas nos textos críticos estampados nos periódicos.

A linguagem rosiana foi imediatamente notada. Lauro Escorel (1946), dias após o lançamento, ressaltou:

Há nesse livro os dois elementos essenciais à autêntica criação literária: o conhecimento pleno, íntimo, do assunto, e o domínio perfeito e seguro da língua, que permite ao escritor ultrapassar a rotina da língua expressional a que está sujeita a maioria dos não-artistas, para invadir, pelos caminhos da fantasia criadora, o próprio terreno da criação lingüística. (...) O sr. J. Guimarães Rosa surge mostrando possuir um profundo conhecimento poético das palavras e das suas possíveis utilizações artísticas; ele as maneja com a mesma volúpia com que o escultor acaricia a argila da qual brotará o esplendor da estátua, sem cair nunca, porém, na grandiloqüência verbalista ou no rebuscamento gratuito, de que o salva um bom gosto literário sempre vigilante e sempre pronto a impedir que a palavra se liberte da idéia e se enamore narcisisticamente de sua própria imagem...

Na verdade, falou-se tanto do autor e do livro, que a impressão que se tem é a de que todos - escritores, críticos, jornalistas, intelectuais e periódicos - queriam marcar presença no debate. E o fenômeno ultrapassou

6. Em 1946, JGR concedeu duas entrevistas: a José César Borba, publicada no dia 19 de maio; a Ascendino Leite, publicada no dia 26 de maio. O depoimento, a pedido de João Condé, saiu no dia 21 de julho - ver referências: Confissões.

7. o Jornal, Rio de Janeiro, 21 abr. 1946. Arq. JGR-IEB/USP-R2. 
os limites do eixo Rio - São Paulo. Falou-se de Sagarana em Fortaleza: Unitário e O Estado; em Paraopeba: Gazeta de Paraopeba; em Santos: O Diário e A Tribuna; em Belo Horizonte: Folha de Minas, Alterosas, O Diário e Estado de Minas; no Recife: Jornal do Commercio; em Porto Alegre: Revista do Globo, ainda em 1946. Ao levantar a fortuna crítica do livro colecionada por Guimarães Rosa, vemos que a intelectualidade da época falava em Sagarana como o assunto mais quente da temporada. Mesmo quem não havia lido os contos não podia ficar de fora. Henrique Pongetti (1946), por exemplo, declarou:

Não li ainda o livro porque ainda não escreveram sobre ele os vinte admiráveis espíritos que escreverão sobre ele nesses próximos sessenta dias, contagiados de um entusiasmo sem vacina, inevitável. Gosto de ler certos livros na segunda edição e de ver certos filmes na "reprise".

Como sabemos, o articulista não precisou esperar muito pela $2^{\underline{a}}$ edição de Sagarana, e logo havia mais que vinte críticos (espíritos admiráveis ou não) falando do livro.

Para comprovar o êxito do livro rosiano, quando da reunião de janeiro de 1947, a Sociedade Felipe d'Oliveira, que, consagradoramente, premiava "o escritor que, tendo ingressado na vida das letras, publicou o melhor livro do ano anterior", concedeu o prêmio de cinco mil cruzeiros a J. Guimarães Rosa, considerado "a mais pujante vocação literária de 1946", ao lado de Afonso Pena Júnior, "fulgurante expressão de nossa cultura". Guimarães Rosa passava a integrar uma galeria de premiados, já habitada por Amando Fontes (Os Corumbas), Gilberto Freyre (Casa-grande e senzala), Rachel de Queiroz (As três Marias), Manuel Bandeira, pelo conjunto de obra, entre outros ilustres da cultura brasileira.

8. O Arq. JGR guarda também vários recortes cujos locais não podemos precisar até pela coincidência de títulos (p. ex.: Diário de notícias - Rio de Janeiro e Salvador). Investigação futura trará essas informações.

9. Os dois melhores livros de 46. Contemplados pela Sociedade Felipe d'Oliveira os senhores Guimarães Rosa e Afonso Pena Jr. Diário da Noite, Rio de Janeiro, 16 jan. 1947. Arq. JGR-IEB/USP-R2. 


\section{A entrada no cânone}

Quase que antecipando a lição de Jauss (1978, p. 73), segundo a qual "a resistência que a obra nova opõe à expectativa de seu primeiro público pode ser tão grande, que um longo processo de recepção será necessário antes que seja assimilado aquilo que era originalmente inesperado, inassimilável”, Agrippino Grieco (1946) disse: "o livro parece-me opulento. Muitos episódios bons e, naturalmente, episódios maus. Há onde se lhe pegue. Existe. Mesmo nas ruins passagens (e que bom trabalho não as tem?), aí está, implícito, um grande livro futuro." (grifo nosso)

Para Renato Almeida (1946), representando ares pós-Estado Novo,

O êxito do livro de contos do sr. J. Guimarães Rosa, "Sagarana", vem sobretudo do motivo. O interesse pelo Brasil, através da sensibilidade ou da interpretação dos que dele se aproximam, emotiva ou analiticamente, ainda é dominante e essencial. Aqueles que acreditaram possível fixarmonos na orla da civilização litorânea e nos mantermos em contato permanente com a Europa, cuja cultura transplantamos para este lado do Atlântico, mas resguardando-a da contaminação da barbaria (sic) nativa, equivocaram-se e permaneceram marginais. (...) A vida dramática da gente do interior, nos países latino-americanos, é uma sugestão imensa e trazê-la à luz é ao mesmo tempo fazer obra de arte e pesquisa sociológica.

Almeida, depois de falar de "corte transversal" na alma da gente do interior, preferiu assegurar um tom político ao debate:

O drama das populações do interior e o equívoco da civilização brasileira mais uma vez se patenteia. Ao invés de orientarmos a marcha do progresso para o interior, de uma forma racional, quer dizer preparando o material humano, deixamo-nos ficar nos contornos urbanos, seja nas zonas favoráveis, onde aumentamos o padrão de vida, e abandonamos o mais até que, pela ordem das coisas, porque Deus é brasileiro, as circunstâncias favoreçam melhores dias.

Estaria, de fato, Almeida distanciado do interesse que alimentou intelectuais e artistas na era estadonovista? Ele ressalta o interesse do livro, mencionando "a vida dramática da gente do interior, nos países latinoamericanos", depois da crítica contida em "fixarmo-nos na orla da civilização 
litorânea", etc., etc. Suas observações parecem aproximar sua leitura de Sagarana das motivações que conduziram os intelectuais para estudos etnológicos, outros acerca da cultura popular, uns tantos para aspectos geográficos, muitos voltados para populações do interior do Brasil, que alimentaram tantas publicações das históricas Coleções (Brasiliana e Documentos Brasileiros) nascidas no Estado Novo.

$\mathrm{Na}$ verdade, a crítica refletia uma atitude de recepção. Sagarana trazia nova seiva para a corrente regionalista, e, por isso, o debate marcou o caráter de exceção, ou de originalidade, contido no livro, que, ao mesmo tempo, vinha ao encontro do interesse pelas regiões remotas, que alimentara a atitude intelectual em passado tão recente.

\section{Conclusão}

Se Sagarana foi acolhido com aplausos e com restrições por parte da crítica também não ficou parado nas prateleiras das livrarias, passando a figurar entre os mais vendidos daquele ano. Para Almeida Fischer (1946), "é verdade que certos críticos e cronistas exageraram um pouco os méritos do livro e se esqueceram de apontar-lhe as deficiências, o que explica, em parte, o sucesso obtido." Alcântara Silveira (1946), talvez mais realista e com uma certa neutralidade, disse: "O que houve no caso de J. Guimarães Rosa, foi apenas coincidência entre a opinião do povo e a do crítico (coisa que raramente acontece) e por isso 'Sagarana' tem sido lido."

A polêmica esteve sempre orientada por uma atitude comparativa, quer com os grandes contistas, quer com os reconhecidos nomes do regionalismo, além de ser ideologizada. Ou seja: o debate foi travado à luz do cânone de até 1946. A partir daí, Sagarana passava a integrar o cânone, agora enriquecido com sua participação.

Abril de 2006, 60 anos do lançamento de Sagarana 
Disponivel em: http://www.letras.ufmg.br/poslit

Abstract: This article examines verified the critical reception of Sagarana, considering the context after the Estado Novo (New State), resulting in its entrance in the canon of the Brazilian Literature.

Key words: narrative - aesthetics of the reception - canon

\section{Referências Bibliográficas}

ALMEIDA FISCHER. O conto na literatura. A Manhã, Rio de Janeiro, p. 14, 23 jun., 1946, p. 14. Letras e Artes. Arq. JGR-IEB/USP-R2.*

ALMEIDA, R. Sagarana. Correio da Manhã, Rio de Janeiro, 30 jun. 1946. Arq. JGR-IEB/USP-R1.

BAKHTIN, M. (V. N. Volochínov). Marxismo e filosofia da linguagem: Problemas fundamentais do método sociológico na ciência da linguagem, $4^{a}$ ed. Trad. Michel Lahud e Yara Frateschi Vieira. São Paulo: Hucitec, 1988.

BORBA, J. C. Histórias de Itaguara e Cordisburgo. Correio da Manhã, Rio de Janeiro, 19 maio 1946. Arq. JGR-IEB/USP-R2.

CARRAZZONI, A. Getúlio Vargas. 2. ed. Rio de Janeiro: José Olympio, 1939.

CASTELLO, J. A. A literatura brasileira. Origens e unidade (1500-1960). São Paulo: Ed. da Universidade de São Paulo, 1999. 2v.

CONFISSÕES - Sagarana. Letras e artes, Rio de Janeiro, 21 jul. 1946. Suplemento de $A$ Manhã. Depoimento de Guimarães Rosa a João Condé. Arq. JGR-IEB/USP-R2.

ESCOREL, L. Nasce um escritor. Correio da Manhã, Rio de Janeiro, 28 abr. 1946. Arq. JGR-R1.

GRIECO, A. Sagarana. OJornal, Rio de Janeiro, 26 abr. 1946. Arq. JGR-IEB/USP-R1.

JAUSS, H. R. Pour une esthétique de la réception. Trad. Claude Maillard. Paris: Gallimard, 1978. (tel, 169).

LAFETÁ, J. L. 1930: a crítica e o Modernismo. 2. ed. São Paulo: Duas Cidades, 2000.

LINS, Á. Uma grande estréia. Correio da Manhã, Rio de Janeiro, 12 abr. 1946. Jornal de crítica. Arq. JGR-IEB/USP-R1.

MONTE A. O Estado Novo e suas diretrizes: estudos politicos e constitucionais. Rio de Janeiro: José Olympio, 1938.

PONGETTI, H. Saúva nos loureiros. O Globo, Rio de Janeiro, 8 maio 1946. Cara ou coroa. Arq. JGR-IEB/USP-R2.

PRIMEIRO editor de "Sagarana" (O). Tribuna da Imprensa, Rio de Janeiro, 10 abr. 1956. Hoje nas Letras. Arq. JGR-IEB/USP/-R1

SODRÉ, N. W. Memórias de um escritor: formação. Rio de Janeiro: Civilização Brasileira, 1970,v. 1.

* $\mathrm{R}$, seguido de número, indica a pasta do arquivo JGR-IEB/USP em que se encontra o documento. 